\title{
Examine the Relationship Between Locus of Control and Happiness Male Physical Education and Non Physical Education Teachers in Yazd Province
}

\author{
Mohammad Rajabi \\ Master of Physical Education and Sport Sciences \\ Iraj Totoonchi \\ Master of Physical Education and Sport Sciences \\ Hasan Fahimdavin \\ Mashhad Islamic Azad University, Department of Physical Education \\ Amir Moghaddam \\ Mashhad Islamic Azad University, Department of Physical Education
}

\begin{abstract}
This study examined the relationship between locus of control and happiness for male physical and non-physical education teachers in Yazd province. A total of 260 teachers (physical education 53 people, non-PE 207) by random sampling, and finally 258 questionnaires were examined. In this study, Pearson correlation method for carrying out the Questionnaire of resources Rotter (short form) and Oxford were used. The results showed a positive relationship between locus of control and happiness $(001 / 0 \mathrm{P}=)$. There is a significant. The findings showed Components of mental health, life satisfaction, self-efficacy and positive role in the happiness of the highest physical and non-physical education teachers have. In addition, the comparative study between the two groups in terms of locus of control, physical education teachers from internal locus of control than non-PE teachers, respectively.
\end{abstract}

Keywords: Happiness, locus of control, physical education teachers, physical education Dbyrghr

DOI: $10.7176 /$ RHSS/9-12-13

Publication date:June $30^{\text {th }} 2019$

\section{Introduction:}

Mental vitality and potential benefits of positive emotions such as happiness, mental health has been in recent years a number of researchers it seems the joy of missing mental health in our society. Research has shown that a Muslim be happy to reduce stress, anxiety and depression is very effective because happiness leads to the secretion of adrenaline and hydrocortisone and reduces stress (Schultz, 2008). Happiness is the most important tips how to obtain, strengthen and factors affecting access to this vital need. The most comprehensive and yet most operational definition Vynhvvn (1984) has In his view, the degree of happiness is said to someone, your whole life is desirable In other words, happiness means that how much a person loves his life Increase the power of thinking, enhance quality and success in business communication and problem-solving power of positive results and the effectiveness of happiness. People with a spirit of optimism Shadhngam daily activities to their biggest concern when dealing with problems large and small have more power to remedy (Ceske, 2008). Lobo black, Sheldon and Shade (2005) model for happiness or unhappiness believe that every person that lives makes Your things in a way that makes her a joy to be preserved People will be happy and healthy with a high sense of responsibility Positive feeling of happiness in life have a tremendous impact on the performance and effectiveness effective. Happy people have a positive attitude and optimistic than their surrounding events and instead of the negative bias towards the events of his life trying to take advantage of the events (Rojas, 2007). One of the intellectual style of source control that can affect the happiness of the people. So the locus of control (internal) can be mankind's authority and self-worth and happiness of any individual. Julia Barnard (2007). Locus of control is important in many aspects of life. Locus of control is a system of beliefs that govern one's behavior and internal control is a personality variables associated with satisfaction (Argyle, Persian translation, 1382). Control up with the better deal, less stress, mental and physical health, strength, aspirations, self-esteem, lower anxiety, hig one of the intellectual style of source control that can affect the happiness of the people. One of the intellectual style of source control that can affect the happiness of the people Positive events of life as a result of careful planning and diligent efforts to obtain their own. The consequences of events in their possession and are proactive in dealing with incidents and try to change the direction of events in their favor and they are positive. People with external locus of control will always feel that in order to change life events and the consequences of not doing it and wait for passing events in their natural form are Therefore, physical education teachers as important elements of education played a significant role in the 
character of their students. Teachers depressed and external locus of control good impression on students and reduces the effectiveness of the individual are not Mzan. It also uses passive in the face of events of the life style, defense mechanisms and to assess their emotional assessment of the events of style. Also in research, Paulo Verma (2009) people believed to be internal factors (effort and skill) most appreciate the freedom and independence of their In contrast, those who believe that the outcome depends on external factors such as luck and fate Less satisfaction with Tommy, Panlz and Klkstvn (2008) happiness and creative ideas associated with internal locus of control Creative thinking and meaningful relationship between internal locus of control and there is a special connection between happiness and individuals for significant internal locus of control is contrary to external locus of control Happy thoughts and behaviors are adaptive and helpful. These people look at things with clear vision Prayer are trying to resolve their issues directly and timely seek help from others. On the other hand, the pessimistic unhappy people think and act, The fantasies plunge, blame themselves and others and work to solve problems persist avoid Lyvbvmsky, et al (2005) This study aimed to investigate the relationship between locus of control and happiness male teachers of physical education and physical education have been Yazd province.

\section{Methodology}

The target population included male physical education and physical education teachers working in education in Yazd province was The sample of 260 randomly selected and tested method.

\section{Instruments}

Information on source control through the questionnaire Rotter's locus of control (short form) have been collected. . Short form test locus of control 13 of the short form of this test on two groups of Iranian students studying in Iran and abroad (America) launched The overall correlation questions for the first group to the second group of 72/0 and 68/0 respectively. . Test-retest reliability correlation between the test scores of the scale range from 34/0 to $80 / 0$ and 60/0 determined for the first group and the second group is reported to $28 / 0$ to $66 / 0$. In the questionnaire, participants rated locus of control, internal locus of control and represent 13 was the lowest score is the highest score indicates external locus of control. Since the Oxford Happiness Questionnaire standard and is used by different people Following favorable results have therefore been used as a Instruments In Ali Pur et al (1379) The reliability of the questionnaire has been estimated by Cronbach's 93/0. As well as for face and content validity of the questionnaire survey of 10 expert psychologist and psychiatrist that has the ability to scale to measure happiness, all confirmed participants (Abedi, 1385). Cronbach's alpha reliability coefficient for this questionnaire 87/0 has reported. Each subject has a minimum score of 0 and a maximum of 87 And it questions the positive mood, efficiency, life satisfaction, self-esteem, mental health and people's happiness. Information collected by the investigator and in groups and Pearson correlation test was used to analyze the data.

\section{Result}

Table 1 - the relationship between locus of control and happiness (Pearson correlation coefficient)

\begin{tabular}{|c|c|c|c|}
\hline P-value & $\begin{array}{c}\text { number of } \\
\text { samples }\end{array}$ & $\begin{array}{c}\text { Pearson's correlation } \\
\text { coefficient }\end{array}$ & $\begin{array}{c}\text { the relationship between } \\
\text { between source and } \\
\text { control }\end{array}$ \\
\hline 0.001 & 258 & -0.498 & Welfare \\
\hline 0.001 & 258 & -0.347 & Life satisfaction \\
\hline 0.001 & 258 & -0.342 & Self-esteem \\
\hline 0.001 & 258 & -0.322 & Effectiveness \\
\hline 0.001 & 258 & -0.392 & Positive mood \\
\hline 0.001 & 258 & -0.375 & mental health \\
\hline
\end{tabular}

As can be seen with regard to level and test the level of $(0.05) \%$ and comparison with the significant level statistically significant relationship between locus of control and happiness there. The negative correlation means that people with high happiness rating received and the so-called internal locus of control a little bit more. Other factors are also significant relationship between happiness and satisfaction with life, self-efficacy, positive mood and mental health of high and low marks in internal locus of control are received.

Table 2 compares the average locus of control in physical education teachers and physical education

\begin{tabular}{|c|c|c|c|c|c|}
\hline P-value & $\mathrm{t}$ & Standard deviation & Average & Field of Study & \\
\hline \multirow{2}{*}{0,0009} & \multirow{2}{*}{2,634} & 1,78 & 3,03 & Physical education teachers & $\begin{array}{c}\text { Locus of } \\
\text { Control } \\
\text { (13 points) }\end{array}$ \\
\cline { 3 - 5 } & & 2,01 & 3,79 & Non-PE teachers & \\
\hline
\end{tabular}

The findings also suggest Type internal locus of control in physical education and physical education teachers 
and physical education teachers this rate is higher. This means that the lower rated Aldebaran physical education in the so-called internal locus of control, and more.

\section{Discussion and conclusion}

Based on the findings that there is a significant the relationship between between locus of control and happiness . As a result of research in the field of research Julia Barnard (2007) and Tommy and Panlz (2008) aligned. The first explanation for the relationship between locus of control and happiness is Internal control as an aspect of personality and a way of coping with stressful events in life is. Those who have internal locus of control are more satisfaction out of life and enjoy greater health and less depression. A second explanation is that people with internal locus of control believe that positive life events resulting in accurate mapping and track your efforts, they obtained. So it can be concluded that people with internal locus of control are of great happiness. The concept of locus of control is of utmost importance that individual decisions in life, empowerment and advancement at work, raising authority, healthy lifestyle choices and responsibility in the effective life So having an internal locus of control is a significant relationship to human happiness and can lead to happiness and self-worth of the authority and Julia Barnard (2007). Physiologically physical activity is one of the factors affecting mental health You could say that exercise can have many benefits on mood and behavior, and in addition, physical exercise, reducing stress, tension and depression and increase self-confidence is. The reason we have chemical reactions in the body. A better feel for chemical reactions, physiological and plasma catecholamines are factors that play an important role in stimulating the secretion of chemicals called endorphins in person during the exercise. This material is bracing factor that brings a sense of satisfaction and tranquility for man. So one of the reasons for engaging in physical activity is very important and Vitality (Schultz, 2005) Also participating in social activities and exercise and exposure to real success Winning and losing enables individuals To take responsibility for their actions and accept the consequences of it and have internal locus of control Achieve better results in competitions, participate in social activities, determined against hardships, and strong goals against restrictions, independence and responsibility and judicious is characteristic of people with internal locus of control. In contrast, individuals with external locus of control, low self-esteem, depressed mood and increased frustration, loneliness and lack of interaction with others and are aggressive spirit (Kasik Sahin, 2008) A second explanation for this hypothesis is that sport and physical education not only as a recreational activity that people affected happiness But also as an educational tool - education, psycho-social objectives that it aims to follow many social power of personality, mental health promotion and internal control location plays an important role.

\section{References:}

- ARGYL,M.(2001)The Psychology,The Science of Happiness and Human Strenghs. NEW YORK. BRUNNER

- Feredrekson BL , ,(2005) : positive emotion builds personal resource and predicts future subjective well- being new Orleans : paper presented at the sixth annual Meeting of the society for personality and social Psychology

- JULIA BARNARD.(2007)Locus of control and its Role in Your Happiness

Whetten, David.A \& kim s. Cameron(1998). Developing Management skills. New York: Addison - Wesley, Wheelan

- Kesici,Sahin .(2008).Democratic teacher beliefs according to the teachers gender and locus of control.Article Type :Report, Publication:Journal of Instructional Psychology , ISSN:0094-1956

- Lyubomirsky,S,Sheldon,K.M,\&Schkade,D. (2005). Pursinghappiness:The architecture of sustainable chane.The General Psychology,9(2),111-131.

-Paolo Verma .(2008).Happiness,Freedom,Control.Journal of Econo mic Behavior \&Organization Volume 71 , Issue2,August 2009, Pages 146-161

Rojas, M. (2007), Heterogeneity in the relationship between income and happiness: A conceptual-referent-theory explanation, Journal of economic psychology, 28: 1- 14.

Sisk, D. (2008), Engaging the Spiritual Intelligence of Gifted Student to Bould Global Awareness, Roeper Review, 30 (1): $24-30$ 